${ }^{3}$ Barrett AJ, Weller E, Rozengurt N, Longhurst P, Humble JG. Amidopyrine agranulocytosis: drug inhibition of granulocyte colonies in the presence of patient's serum. Br Med 7 1976;ii :850-851.

4 Tactle R, Lane TA, Mendelsohn J. Drug-induced agranulocytosis: in vitro evidence for immune suppression of granulopoiesis and a crossreacting lymphocyte antibody. Blood 1979;54:501-512.

5 Sutherland R, Vincent PC, Raik E, Burgess K. Quinine-induced agranulocytosis: toxic effect of quinine bisulphate on bone marrow cultures in vitro. $\mathrm{Br} M e d \mathcal{F} 1977 ; \mathrm{i}: 605-607$.

- Howell A, Gumpel JM, Watts RWE. Depression of bone marrow colony formation in gold-induced neutropenia. $B r$ Med $\mathcal{F} 1975 ; \mathrm{i}: 432-434$.

${ }^{7}$ Heimpel H, Kubanek B. Pathophysiology of aplastic anaemia. $\mathrm{Br} f$ Haematol $1975 ; 31$ suppl:57-68.

${ }^{8}$ Ratzan RJ, Moore MAS, Yunis AA. Effect of chloramphenicol and thiamphenicol on the in vitro colony-forming cell. Blood 1974:43: 363-369.

9 Yunis AA. Chloramphenicol-induced bone marrow suppression. Seminars in Haematology 1973;10:225-234.

${ }^{10}$ Howell A, Andrews TM, Watts RWE. Bone marrow cells resistant to chloramphenicol in chloramphenicol-induced aplastic anaemia. Lancet 1975 ; : $65-69$.

11 Yunis AA. Chloramphenicol toxicity. In: Girdwood RH, ed. Blood Disorders Due to Drugs and Other Agents. Amsterdam: Excerpta Medica, 1973:107-26.

12 Nagao T, Mauer AM. Concordance for drug-induced aplastic anaemia in identical twins. $N$ Engl $\mathcal{F}$ Med $1969 ; 281: 7-11$.

13 Nora AH, Fernbach DJ. Acquired aplastic anaemia in children. Tex Med $1969 ; 65: 38-43$.

14 Rosenthal RL, Blackman A. Bone-marrow hypoplasia following use of chloramphenicol eye drops. $\mathcal{F} A M A$ 1965;191:136-137.

15 Ryrie DR, Fletcher J, Langman MJS, Daniels HE. Chloramphenicol over the counter. Lancet $1973 ; \mathrm{i}: 150$.

${ }^{16}$ Cunningham JL, Leyland MJ, Delamore IW, Price Evans DA. Acetanilide oxidation in phenylbutazone-associated hypoplastic anaemia. $\mathrm{Br} \mathrm{Med} \mathcal{F}$ 1974 ;iii:313-317.

\section{Volkmann's ischaemic contracture}

Paralysis and contracture of muscles of an injured limb were first described in 1881 by Volkmann, who blamed interruption of the blood supply by tight bandages. Though studies by Littlewood $^{1}$ and Murphy ${ }^{2}$ suggested that a rise in pressure in the tissues beneath the fascia was responsible for the vascular embarrassment-Murphy even suggested fasciotomy for its treatment-surgeons were distracted by their experience of arterial spasm in vascular injuries in the first world war. The spasm was thought to be due to a nervous reflex conducted by the sympathetic system. In 1940 Lloyd Griffiths ${ }^{3}$ said that Volkmann's ischaemic contracture was due solely to arterial injury with reflex spasm of the collateral vessels. This is still taught to medical students, even though arterial spasm cannot be produced by sympathetic stimulation, directly or reflexly, or relieved by interrupting the sympathetic action.

Volkmann's contracture is simply a consequence of the swelling of soft tissues in an unyielding osteofascial compartment. It may result from injury to the artery proximal to the compartment or from direct insult to the compartment itself. The condition is seen most often as a complication of supracondylar fractures, but it may occur in many other fractures in the arm or leg. Volkmann's contracture represents a middle course in the response to trauma-the mildest course resulting in complete recovery, the most severe giving gangrene and possibly the full-blown features of the crush syndrome. ${ }^{4}$

The artery may be damaged either at the moment of injury or in the subsequent manipulations of the fracture. A minute intimal tear is enough for clotting to occur in the main vessel and also in the collateral vessels near by. In such cases the treatment is to remove the clot, excise the damaged segment, and restore the continuity of the artery. Holden ${ }^{5}$ believes that simply stretching the vessel without an intimal tear can also induce ischaemia. Apparently if the intra-arterial pressure is reduced the vessel may collapse because of the unopposed tension in the vessel walls. This critical closure may be diagnosed by exploring the vessel and overcome by injecting a bolus of fluid through the narrow segment. Whatever the mechanism, however, successful treatment will clearly depend on recognising the syndrome quickly and referring the patient promptly to a vascular surgeon.

Volkmann's contracture affects muscles that lie within confined osteofascial compartments: the anterior tibial, the peroneal, and the deep posterior compartments of the leg and the flexor and extensor compartments of the forearm. The capillary walls are damaged by ischaemia and by allowing fluids and colloids to escape into the tissues, with subsequent increase in their volume. The greater the damage the more the tissues swell, in turn causing more ischaemic damage. The treatment is generous fasciotomy to allow the tissues to swell without the dangerous rise of pressure.

Mubarak and Carroll ${ }^{6}$ recently reported no decline in 21 years in the frequency of Volkmann's ischaemic contracture in the Hospital for Sick Children, Toronto, despite the attention given to the problem. The condition is relatively uncommon, but it should always be kept in mind in any patient with an injured limb. The signs and symptoms are variable and unreliable. Pain is the most common feature; not relieved by rest, it becomes progressively more severe and is made worse by passive stretching of the ischaemic muscles. Unfortunately, however, pain is sometimes absent altogether. Once the diagnosis is suspected the doctor should look for abnormal physical signs. Nerve tissue is the most sensitive to ischaemia, and a careful examination of those nerves passing through the area under suspicion may give an early diagnostic indication. Abnormalities of the peripheral pulses and skin colour are less reliable signs, but both should be examined. The intracompartmental pressures can be measured by the wick catheter techniques, ${ }^{4}$ but these are not usually available to surgeons; thus clinical judgment remains the most important factor in assessing and preventing the disorder.

Young doctors working in accident and emergency departments are the most likely to see patients with this condition, and they need to be reminded of the possibility of complications. They should seek help at once if they are suspicious, for any reduction in the numbers of patients suffering from Volkmann's ischaemic contracture must come from the vigilance and training of these doctors. No patient should have pain from a limb in plaster. If he has, he must be seen quickly and his limb carefully examined, if necessary with the plaster removed. The price of failure is high: a ruined limb for which surgery can offer only limited improvement.

${ }^{1}$ Littlewood H. Some complications following on injuries about the elbow-joint and their treatment. Lancet 1900; :290-2.

${ }^{2}$ Murphy JB. Myositis. FAMA 1914;63:1249-55.

${ }^{3}$ Griffiths DLl. Volkmann's ischaemic contracture. Br f Surg 1940;28: 239-60.

${ }^{4}$ Anonymous. Muscle compartment syndrome. $\mathrm{Br} \mathrm{Med} \mathcal{F}$ 1979;ii:818.

5 Holden CEA. The pathology and prevention of Volkmann's ischaemic contracture. F Bone foint Surg (Br) $1979 ; 61$ B :269-300.

${ }^{6}$ Mubarak SJ, Carroll NC. Volkmann's contracture in children: aetiology and prevention. F Bone Surg $(B r) 1979 ; 61 B: 285-93$. 